\title{
Association Between Anemia and Fatigue in Hospitalized Patients: Does the Measure of Anemia Matter?
}

\author{
Micah T. Prochaska, MD, MS ${ }^{1 *}$, Richard Newcomb, BA², Graham Block, BA², Brian Park, BA³, David O. Meltzer MD, PhD
}

${ }^{1}$ Department of Medicine, Section of Hospital Medicine, The University of Chicago, Chicago, Illinois; ${ }^{2}$ Pritzker School of Medicine, The University of Chicago, Chicago, Illinois; ${ }^{3}$ Drexel University College of Medicine, Philadelphia, Pennsylvania.

\begin{abstract}
BACKGROUND: Restrictive blood transfusion practices in hospitalized patients with anemia have reduced the use of transfusion. Consequently, hospitalized patients are more likely to have lower hemoglobin $(\mathrm{Hb})$ concentrations. Lower $\mathrm{Hb}$ is associated with increased fatigue in ambulatory patients. However, it is not known whether anemia is associated with fatigue in hospitalized patients. It is also unclear how to best measure anemia in hospitalized patients because $\mathrm{Hb}$ levels generally vary over a hospital stay.
\end{abstract}

OBJECTIVE: To assess multiple $\mathrm{Hb}$-based measures of anemia in hospitalized patients and test whether these are associated with fatigue.

DESIGN: Prospective observational study.

SETTING: Urban, academic medical center.

PATIENTS: Hospitalized general medicine patients, age $\geq 50$ years, with any $\mathrm{Hb}<9 \mathrm{~g} / \mathrm{dL}$.

INTERVENTION: Patients' anemia-related fatigue was measured during hospitalization.
MEASUREMENTS: Measures of anemia were created for each patient based on the $\mathrm{Hb}$ values from their hospitalization (mean, median, minimum, maximum, admission, and discharge). Fatigue was measured using the Functional Assessment of Chronic Illness Therapy (FACIT)-Fatigue subscale.

RESULTS: Seven hundred eighty-four patients participated. Minimum $\mathrm{Hb}$ was strongly associated with fatigue. Patients with a minimum $\mathrm{Hb}$ of $<8 \mathrm{~g} / \mathrm{dL}$ had higher fatigue levels (mean FACIT [standard deviation] Hb $<7 \mathrm{~g} / \mathrm{dL}: 25$ [13], $7 \mathrm{~g} /$ $\mathrm{dL} \leq \mathrm{Hb}<8 \mathrm{~g} / \mathrm{dL}: 25$ [14] Hb $\geq 8 \mathrm{~g} / \mathrm{dL}: 29$ [14], $P \leq 0.001$ ) and were more likely to report high levels of fatigue (FACIT-Fatigue $<27$ ) (56\% vs $41 \%$; $P=0.002$ ). Mean $\mathrm{Hb}$ had a less robust association with fatigue than minimum $\mathrm{Hb}$, and no other measure of $\mathrm{Hb}$ was associated with patients' fatigue levels.

CONCLUSION: Minimum $\mathrm{Hb}$ is associated with fatigue while hospitalized and may help identify patients for interventions to address anemia-related fatigue. Journal of Hospital Medicine 2017;12: 898-904. Published online first September 6, 2017. (c) 2017 Society of Hospital Medicine
Fatigue is the most common clinical symptom of anemia and is a significant concern to patients. ${ }^{1,2}$ In ambulatory patients, lower hemoglobin $(\mathrm{Hb})$ concentration is associated with increased fatigue. ${ }^{2,3}$ Accordingly, therapies that treat anemia by increasing $\mathrm{Hb}$ concentration, such as erythropoiesis stimulating agents, ${ }^{4-7}$ often use fatigue as an outcome measure.

In hospitalized patients, transfusion of red blood cell increases $\mathrm{Hb}$ concentration and is the primary treatment for anemia. However, the extent to which transfusion and changes in $\mathrm{Hb}$ concentration affect hospitalized patients' fatigue levels is not well established. Guidelines support transfusing patients with symptoms of anemia, such as fatigue, on the assumption that the increased oxygen delivery will improve the symptoms of anemia. While transfusion studies in hospitalized patients have consistently reported that transfusion at lower or "restrictive" $\mathrm{Hb}$ concentrations is safe compared with transfusion at higher $\mathrm{Hb}$ concentrations, ${ }^{8-10}$ these studies have mainly used

\footnotetext{
*Address for correspondence and reprint requests: Micah T. Prochaska, MD, MS, University of Chicago, 5841 S. Maryland Avenue, MC 5000, Chicago, IL 60637; Telephone: 773-702-6988; Fax: 773-795-7398; E-mail: mprochas@ medicine.bsd.uchicago.edu
}

Additional Supporting Information may be found in the online version of this article.

Received: January 12, 2017; Revised: April 10, 2017;

Accepted: April 16, 2017

2017 Society of Hospital Medicine DOI 10.12788/jhm.2832 cardiac events and mortality as outcomes rather than patient symptoms, such as fatigue. Nevertheless, they have resulted in hospitals increasingly adopting restrictive transfusion policies that discourage transfusion at higher $\mathrm{Hb}$ levels. ${ }^{11,12}$ Consequently, the rate of transfusion in hospitalized patients has decreased, ${ }^{13}$ raising questions of whether some patients with lower $\mathrm{Hb}$ concentrations may experience increased fatigue as a result of restrictive transfusion policies. Fatigue among hospitalized patients is important not only because it is an adverse symptom but because it may result in decreased activity levels, deconditioning, and losses in functional status. ${ }^{14,15}$

While the effect of alternative transfusion policies on fatigue in hospitalized patients could be answered by a randomized clinical trial using fatigue and functional status as outcomes, an important first step is to assess whether the $\mathrm{Hb}$ concentration of hospitalized patients is associated with their fatigue level during hospitalization. Because hospitalized patients often have acute illnesses that can cause fatigue in and of themselves, it is possible that anemia is not associated with fatigue in hospitalized patients despite anemia's association with fatigue in ambulatory patients. Additionally, $\mathrm{Hb}$ concentration varies during hospitalization, ${ }^{16}$ raising the question of what measures of $\mathrm{Hb}$ during hospitalization might be most associated with anemia-related fatigue.

The objective of this study is to explore multiple $\mathrm{Hb}$ measures in hospitalized medical patients with anemia and 
test whether any of these $\mathrm{Hb}$ measures are associated with patients' fatigue level.

\section{METHODS}

\section{Study Design}

We performed a prospective, observational study of hospitalized patients with anemia on the general medicine services at The University of Chicago Medical Center (UCMC). The institutional review board approved the study procedures, and all study subjects provided informed consent.

\section{Study Eligibility}

Between April 2014 and June 2015, all general medicine inpatients were approached for written consent for The University of Chicago Hospitalist Project, ${ }^{17}$ a research infrastructure at UCMC. Among patients consenting to participate in the Hospitalist Project, patients were eligible if they had $\mathrm{Hb}<9 \mathrm{~g} / \mathrm{dL}$ at any point during their hospitalization and were age $\geq 50$ years. $\mathrm{Hb}$ concentration of $<9 \mathrm{~g} / \mathrm{dL}$ was chosen to include the range of $\mathrm{Hb}$ values covered by most restrictive transfusion policies. ${ }^{8-10,18}$ Age $\geq 50$ years was an inclusion criteria because anemia is more strongly associated with poor outcomes, including functional impairment, among older patients compared with younger patients..$^{14,19-21}$ If patients were not eligible for inclusion at the time of consent for the Hospitalist Project, their $\mathrm{Hb}$ values were reviewed twice daily until hospital discharge to assess if their $\mathrm{Hb}$ was $<9 \mathrm{~g} /$ dL. Proxies were sought to answer questions for patients who failed the Short Portable Mental Status Questionnaire. ${ }^{22}$

\section{Patient Demographic Data Collection}

Research assistants abstracted patient age and sex from the electronic health record (EHR), and asked patients to self-identify their race. The individual comorbidities included as part of the Charlson Comorbidity Index were identified using International Classification of Diseases, 9th Revision codes from hospital administrative data for each encounter and specifically included the following: myocardial infarction, congestive heart failure, peripheral vascular disease, cerebrovascular disease, dementia, chronic pulmonary disease, rheumatic disease, peptic ulcer disease, liver disease, diabetes, hemiplegia and/or paraplegia, renal disease, cancer, and human immunodeficiency virus/acquired immunodeficiency syndrome. ${ }^{23}$ We also used Healthcare Cost and Utilization Project (www.hcup-us.ahrq.gov/toolssoftware/ccs/ ccs.jsp) diagnosis categories to identify whether patients had sickle cell (SC) anemia, gastrointestinal bleeding (GIB), or a depressive disorder (DD) because these conditions are associated with anemia (SC and GIB) and fatigue (DD). ${ }^{24}$

\section{Measuring Anemia}

$\mathrm{Hb}$ measures were available only when hospital providers ordered them as part of routine practice. The first $\mathrm{Hb}$ concentration $<9 \mathrm{~g} / \mathrm{dL}$ during a patient's hospitalization, which made them eligible for study participation, was obtained through manual review of the EHR. All additional $\mathrm{Hb}$ val- ues during the patient's hospitalization were obtained from the hospital's administrative data mart. All $\mathrm{Hb}$ values collected for each patient during the hospitalization were used to calculate summary measures of $\mathrm{Hb}$ during the hospitalization, including the mean $\mathrm{Hb}$, median $\mathrm{Hb}$, minimum $\mathrm{Hb}$, maximum $\mathrm{Hb}$, admission (first recorded) $\mathrm{Hb}$, and discharge (last recorded) $\mathrm{Hb}$. $\mathrm{Hb}$ measures were analyzed both as a continuous variable and as a categorical variable created by dividing the continuous $\mathrm{Hb}$ measures into integer ranges of 3 groups of approximately the same size.

\section{Measuring Fatigue}

Our primary outcome was patients' level of fatigue reported during hospitalization, measured using the Functional Assessment of Chronic Illness Therapy (FACIT)-Anemia questionnaire. Fatigue was measured using a 13-question fatigue subscale, ${ }^{1,2,25}$ which measures fatigue within the past 7 days. Scores on the fatigue subscale range from 0 to 52 , with lower scores reflecting greater levels of fatigue. As soon as patients met the eligibility criteria for study participation during their hospitalization (age $\geq 50$ years and $\mathrm{Hb}<9 \mathrm{~g} / \mathrm{dL}$ ), they were approached to answer the FACIT questions. Values for missing data in the fatigue subscale for individual subjects were filled in using a prorated score from their answered questions as long as $>50 \%$ of the items in the fatigue subscale were answered, in accordance with recommendations for addressing missing data in the FACIT. ${ }^{26}$ Fatigue was analyzed as a continuous variable and as a dichotomous variable created by dividing the sample into high (FACIT $<27$ ) and low (FACIT 227 ) levels of fatigue based on the median FACIT score of the population. Previous literature has shown a FACIT fatigue subscale score between 23 and 26 to be associated with an Eastern Cooperative Oncology Group (ECOG) ${ }^{27}$ C Performance Status rating of 2 to $3^{3}$ compared to scores $\geq 27$.

\section{Statistical Analysis}

Statistical analysis was performed using Stata statistical software (StataCorp, College Station, Texas). Descriptive statistics were used to characterize patient demographics. Analysis of variance was used to test for differences in the mean fatigue levels across $\mathrm{Hb}$ measures. $\chi^{2}$ tests were performed to test for associations between high fatigue levels and the $\mathrm{Hb}$ measures. Multivariable analysis, including both linear and logistic regression models, were used to test the association of $\mathrm{Hb}$ concentration and fatigue. $P$ values $<0.05$ using a 2 -tailed test were deemed statistically significant.

\section{RESULTS}

\section{Patient Characteristics}

During the study period, 8559 patients were admitted to the general medicine service. Of those, 5073 (59\%) consented for participation in the Hospitalist Project, and 3670 (72\%) completed the Hospitalist Project inpatient interview. Of these patients, 1292 (35\%) had $\mathrm{Hb}<9 \mathrm{~g} / \mathrm{dL}$, and 784 (61\%) were 50 years or older and completed the FACIT questionnaire.

Table 1 reports the demographic characteristics and comorbidities for the sample, the mean (standard deviation 
[SD]) for the $6 \mathrm{Hb}$ measures, and mean (SD) and median FACIT scores.

\section{Bivariate Association of Fatigue and $\mathrm{Hb}$}

Categorizing patients into low, middle, or high $\mathrm{Hb}$ for each of the $6 \mathrm{Hb}$ measures, minimum $\mathrm{Hb}$ was strongly associated with fatigue, with a weaker association for mean $\mathrm{Hb}$ and no statistically significant association for the other measures.

\section{Minimum $\mathrm{Hb}$}

Patients with a minimum $\mathrm{Hb}<7 \mathrm{~g} / \mathrm{dL}$ and patients with $\mathrm{Hb}$ $7-8 \mathrm{~g} / \mathrm{dL}$ had higher fatigue levels (FACIT $=25$ for each) than patients with a minimum $\mathrm{Hb} \geq 8 \mathrm{~g} / \mathrm{dL}$ (FACIT $=29 ; \mathrm{P}$ $<0.001$; Table 2). When excluding patients with SC and/or GIB because their average minimum $\mathrm{Hb}$ differed from the average minimum $\mathrm{Hb}$ of the full population $(P<0.001)$, patients with a minimum $\mathrm{Hb}<7 \mathrm{~g} / \mathrm{dL}$ or $7-8 \mathrm{~g} / \mathrm{dL}$ had even higher fatigue levels (FACIT $=23$ and FACIT $=24$, respectively), with no change in the fatigue level of patients with a minimum $\mathrm{Hb} \geq 8 \mathrm{~g} / \mathrm{dL}$ (FACIT $=29 ; P<0.001$; Table 2). Lower minimum $\mathrm{Hb}$ continued to be associated with higher fatigue levels when analyzed in $0.5 \mathrm{~g} / \mathrm{dL}$ increments (Figure).

Lower values of minimum $\mathrm{Hb}$ were also associated with patients reporting high fatigue levels (FACIT <27). Fatigue levels were high for $50 \%$ of patients with a minimum $\mathrm{Hb}$ $<7 \mathrm{~g} / \mathrm{dL}$ and $56 \%$ of patients with a minimum $\mathrm{Hb} 7-8 \mathrm{~g} / \mathrm{dL}$ compared with only $41 \%$ of patients with a minimum $\mathrm{Hb} \geq 8$ $\mathrm{g} / \mathrm{dL}(P<0.002)$. Excluding patients with SC and/or GIB, fatigue levels were high for $54 \%$ of patients with a minimum $\mathrm{Hb}<7 \mathrm{~g} / \mathrm{dL}$ and $57 \%$ of patients with a minimum $\mathrm{Hb} 7-8 \mathrm{~g} /$ dL compared with $41 \%$ of patients with a minimum $\mathrm{Hb} \geq 8$ $\mathrm{g} / \mathrm{dL}(P<0.001$; Table 2$)$.

\section{Mean $\mathrm{Hb}$ and Other Measures}

Fatigue levels were high for $47 \%$ of patients with a mean $\mathrm{Hb}<8 \mathrm{~g} / \mathrm{dL}$ and $53 \%$ of patients with a mean $\mathrm{Hb} 8-9 \mathrm{~g} / \mathrm{dL}$ compared with $43 \%$ of patients with a mean $\mathrm{Hb} \geq 9 \mathrm{~g} / \mathrm{dL}$ ( $P$ $=0.05)$. However, the association between high fatigue and mean $\mathrm{Hb}$ was not statistically significant when patients with SC and/or GIB were excluded (Table 2). None of the other 4 $\mathrm{Hb}$ measures was significantly associated with fatigue.

\section{Linear Regression of Fatigue on $\mathrm{Hb}$}

In linear regression models, minimum $\mathrm{Hb}$ consistently predicted patient fatigue, mean $\mathrm{Hb}$ had a less robust association with fatigue, and the other $\mathrm{Hb}$ measures were not associated with patient fatigue. Increases in minimum $\mathrm{Hb}$ (analyzed as a continuous variable) were associated with reduced fatigue (higher FACIT score; $\beta=1.4 ; P=0.005)$. In models in which minimum $\mathrm{Hb}$ was a categorical variable, patients with a minimum $\mathrm{Hb}$ of $<7 \mathrm{~g} / \mathrm{dL}$ or $7-8 \mathrm{~g} / \mathrm{dL}$ had greater fatigue (lower FACIT score) than patients whose minimum $\mathrm{Hb}$ was $\geq 8 \mathrm{~g} / \mathrm{dL}$ ( $\mathrm{Hb}<7$ $\mathrm{g} / \mathrm{dL}: \beta=-4.2 ; P \leq 0.001 ; \mathrm{Hb} 7-8 \mathrm{~g} / \mathrm{dL}: \beta=-4.1 ; P<0.001)$. These results control for patients' age, sex, individual comorbidities, and whether their minimum $\mathrm{Hb}$ occurred before or after the measurement of fatigue during hospitalization (Mod-
TABLE 1. Patient Characteristics

\begin{tabular}{|c|c|}
\hline Total $\mathrm{N}=784$ & $\mathrm{~N}(\%)$ \\
\hline Female & $447(57)$ \\
\hline Age-Mean \pm SD (years) & $66 \pm 11$ \\
\hline \multicolumn{2}{|l|}{ Race } \\
\hline American Indian or Alaskan Native & $3(<1)$ \\
\hline Asian & $12(2)$ \\
\hline Black or African American & $507(65)$ \\
\hline White & $212(27)$ \\
\hline Multiple reported races & $8(1)$ \\
\hline Don't know or refused & $42(5)$ \\
\hline \multicolumn{2}{|l|}{ Ethnicity } \\
\hline Hispanic or Latino & $46(6)$ \\
\hline Not Hispanic or Latino & $711(91)$ \\
\hline Don't know or refused & $27(3)$ \\
\hline \multicolumn{2}{|l|}{ Admission comorbidities } \\
\hline Myocardial infarction & $59(8)$ \\
\hline Congestive heart failure & $251(32)$ \\
\hline Peripheral vascular disease & $71(9)$ \\
\hline Cerebrovascular disease & $25(3)$ \\
\hline Dementia & $0(0)$ \\
\hline Chronic pulmonary disease & $211(27)$ \\
\hline Rheumatic disease & $40(5)$ \\
\hline Peptic ulcer disease & $47(6)$ \\
\hline Liver disease & $126(16)$ \\
\hline Diabetes & $344(43)$ \\
\hline Hemiplegia and/or paraplegia & $10(1)$ \\
\hline Renal disease & $165(21)$ \\
\hline Cancer & $134(17)$ \\
\hline AIDS/HIV & $10(1)$ \\
\hline Sickle cell anemia & $21(3)$ \\
\hline Gastrointestinal bleeding & $98(13)$ \\
\hline Depressive disorder & $103(13)$ \\
\hline \multicolumn{2}{|l|}{ Hemoglobin measures $\pm \mathrm{SD}(\mathrm{g} / \mathrm{dL})$} \\
\hline Mean & $8.5 \pm 0.8$ \\
\hline Median & $8.4 \pm 0.8$ \\
\hline Minimum & $7.3 \pm 1.1$ \\
\hline Maximum & $9.8 \pm 1.5$ \\
\hline Admission & $8.9 \pm 1.8$ \\
\hline Discharge & $8.5 \pm 0.9$ \\
\hline Transfusion during hospitalization & $289(35)$ \\
\hline \multicolumn{2}{|c|}{ FACIT-Fatigue subscale score (range 0-52) } \\
\hline Mean \pm SD & $26 \pm 14$ \\
\hline Median (IQR1-IQR3) & $27(15-37)$ \\
\hline
\end{tabular}

NOTE: Abbreviations: AIDS/HIV, acquired immunodeficiency syndrome/human immunodeficiency virus; FACIT, Functional Assessment of Chronic IIIness Therapy; IQR, interquartile range; SD, standard deviation.

el 1), and the results are unchanged when also controlling for the number of $\mathrm{Hb}$ laboratory draws patients had during their hospitalization (Model 2; Table 3). In a stratified analysis excluding patients with either SC and/or GIB, changes in minimum $\mathrm{Hb}$ were associated with larger changes in patient fatigue levels (Supplemental Table 1). We also stratified our analysis to include only patients whose minimum $\mathrm{Hb}$ occurred before the measurement of their fatigue level during hospitalization to avoid a spurious association of fatigue with minimum $\mathrm{Hb}$ occurring after fatigue was measured. In both Models 1 and 2, 
TABLE 2. Bivariate Analysis of Fatigue and Hemoglobin Measures

\begin{tabular}{|c|c|c|c|c|c|c|c|c|c|c|c|}
\hline \multirow[b]{2}{*}{$\begin{array}{l}\text { Hemoglobin } \\
\text { Measure }\end{array}$} & \multirow[b]{2}{*}{ Range } & \multicolumn{5}{|c|}{ Full Population ( $\mathrm{N}=784$ ) } & \multicolumn{5}{|c|}{ Excluding SC and/or GIB Patients ( $N=666)$} \\
\hline & & $\begin{array}{l}\text { Subjects } \\
(n=784)\end{array}$ & $\begin{array}{l}\text { Mean Fatigue } \\
\text { Score }^{\mathrm{a}} \text { (s.e) }\end{array}$ & $P^{b}$ & $\begin{array}{c}\text { Percent High } \\
\text { Fatigue, } \\
\text { FACIT }<27\end{array}$ & $P^{c}$ & $\begin{array}{l}\text { Subjects } \\
(\mathrm{n}=594)\end{array}$ & $\begin{array}{l}\text { Mean Fatigue } \\
\text { Score }^{a} \text { (s.e) }\end{array}$ & $P^{b}$ & $\begin{array}{c}\text { Percent High Fatigue, } \\
\text { FACIT }<27\end{array}$ & $P^{c}$ \\
\hline \multirow[t]{3}{*}{ Mean } & $\mathrm{Hb}<8 \mathrm{~g} / \mathrm{dL}$ & 214 & $26(1.0)$ & .07 & 47 & .05 & 147 & $25(1.2)$ & .06 & 51 & .09 \\
\hline & $\begin{array}{c}8 \mathrm{~g} / \mathrm{dL} \leq \mathrm{Hb} \\
<9 \mathrm{~g} / \mathrm{dL}\end{array}$ & 370 & $25(0.7)$ & & 53 & & 283 & $25(0.8)$ & & 53 & \\
\hline & $\mathrm{Hb} \geq 9 \mathrm{~g} / \mathrm{dL}$ & 200 & $28(1.0)$ & & 43 & & 164 & $28(1.1)$ & & 43 & \\
\hline \multirow[t]{3}{*}{ Median } & $\mathrm{Hb}<8 \mathrm{~g} / \mathrm{dL}$ & 222 & $26(1.0)$ & .47 & 48 & .65 & 157 & $24(1.1)$ & .3 & 52 & .81 \\
\hline & $\begin{array}{c}8 \mathrm{~g} / \mathrm{dL} \leq \mathrm{Hb}< \\
9 \mathrm{~g} / \mathrm{dL}\end{array}$ & 380 & $26(0.7)$ & & 50 & & 291 & $26(0.8)$ & & 50 & \\
\hline & $\mathrm{Hb} \geq 9 \mathrm{~g} / \mathrm{dL}$ & 182 & $27(1.0)$ & & 46 & & 146 & $27(1.1)$ & & 48 & \\
\hline \multirow[t]{3}{*}{ Minimum } & $\mathrm{Hb}<7 \mathrm{~g} / \mathrm{dL}$ & 284 & $25(0.8)$ & $<.001$ & 50 & .002 & 180 & $23(0.9)$ & $<.001$ & 54 & $<.001$ \\
\hline & $\begin{array}{l}7 \mathrm{~g} / \mathrm{dL} \leq \mathrm{Hb} \\
<8 \mathrm{~g} / \mathrm{dL}\end{array}$ & 234 & $25(0.9)$ & & 56 & & 181 & $24(1.0)$ & & 57 & \\
\hline & $\mathrm{Hb} \geq 8 \mathrm{~g} / \mathrm{dL}$ & 266 & $29(0.9)$ & & 41 & & 233 & $29(0.9)$ & & 41 & \\
\hline \multirow[t]{3}{*}{ Maximum } & $\mathrm{Hb}<9 \mathrm{~g} / \mathrm{dL}$ & 212 & $27(1.0)$ & .27 & 44 & .17 & 159 & $26(1.1)$ & .32 & 47 & .36 \\
\hline & $\begin{array}{c}9 \mathrm{~g} / \mathrm{dL} \leq \mathrm{Hb} \\
<10 \mathrm{~g} / \mathrm{dL}\end{array}$ & 278 & $26(0.8)$ & & 49 & & 203 & $26(0.9)$ & & 49 & \\
\hline & $\mathrm{Hb} \geq 10 \mathrm{~g} / \mathrm{dL}$ & 294 & $25(0.8)$ & & 52 & & 232 & $25(0.9)$ & & 53 & \\
\hline \multirow[t]{3}{*}{ Admission } & $\mathrm{Hb}<8 \mathrm{~g} / \mathrm{dL}$ & 196 & $26(1.0)$ & .27 & 47 & .37 & 112 & $24(1.2)$ & .23 & 51 & .72 \\
\hline & $\begin{array}{c}8 \mathrm{~g} / \mathrm{dL} \leq \mathrm{Hb} \\
<10 \mathrm{~g} / \mathrm{dL}\end{array}$ & 384 & $27(0.7)$ & & 53 & & 309 & $26(0.8)$ & & 49 & \\
\hline & $\mathrm{Hb} \geq 10 \mathrm{~g} / \mathrm{dL}$ & 204 & $25(1.0)$ & & 49 & & 173 & $25(1.0)$ & & 52 & \\
\hline \multirow[t]{3}{*}{ Discharge } & $\mathrm{Hb}<8 \mathrm{~g} / \mathrm{dL}$ & 244 & $26(0.9)$ & .83 & 49 & .86 & 160 & $25(1.1)$ & .59 & 52 & .66 \\
\hline & $\begin{array}{l}8 \mathrm{~g} / \mathrm{dL} \leq \mathrm{Hb} \\
<9 \mathrm{~g} / \mathrm{dL}\end{array}$ & 267 & $26(0.8)$ & & 50 & & 292 & $26(0.8)$ & & 50 & \\
\hline & $\mathrm{Hb} \geq 9 \mathrm{~g} / \mathrm{dL}$ & 273 & $27(0.9)$ & & 47 & & 142 & $26(1.1)$ & & 50 & \\
\hline
\end{tabular}

aHigher fatigue scores equate with lower fatigue.

b $P$ values for analysis of variance.

c $P$ values for $\chi 2$.

NOTE: Abbreviations: FACIT, Functional Assessment of Chronic IIIness Therapy; GIB, gastrointestinal bleeding; Hb, hemoglobin; SC, sickle cell anemia

minimum $\mathrm{Hb}$ remained a predictor of patients' fatigue levels with similar effect sizes, although in Model 2, the results did not quite reach a statistically significant level, in part due to larger confidence intervals from the smaller sample size of this stratified analysis (Supplemental Table 2a). We further stratified this analysis to include only patients whose transfusion, if they received one, occurred after their minimum $\mathrm{Hb}$ and the measurement of their fatigue level to account for the possibility that a transfusion could affect the fatigue level patients report. In this analysis, most of the estimates of the effect of minimum $\mathrm{Hb}$ on fatigue were larger than those seen when only analyzing patients whose minimum $\mathrm{Hb}$ occurred before the measurement of their fatigue level, although again, the smaller sample size of this additional stratified analysis does produce larger confidence intervals for these estimates (Supplemental Table 2b).
Analyzed as a categorical variable, a mean $\mathrm{Hb}<8 \mathrm{~g} / \mathrm{dL}$ or $8-9 \mathrm{~g} / \mathrm{dL}$ was also associated with higher levels of fatigue compared with patients whose mean $\mathrm{Hb}$ is $\geq 9 \mathrm{~g} / \mathrm{dL}$ in both Models 1 and 2, although the results were only statistically significant for patients with a mean $\mathrm{Hb} 8-9 \mathrm{~g} / \mathrm{dL}(\beta=-2.5 ; P$ $<0.04$; Table 3 ). There were no statistically significant associations between mean $\mathrm{Hb}$ and fatigue when excluding $\mathrm{SC}$ and/or GIB patients (Supplemental Table 3).

$\mathrm{No} \mathrm{Hb}$ measure other than minimum or mean had significant association with patient fatigue levels in linear regression models.

\section{Logistic Regression of High Fatigue Level on $\mathrm{Hb}$}

Using logistic regression, minimum $\mathrm{Hb}$ analyzed as a categorical variable predicted increased odds of a high fatigue 


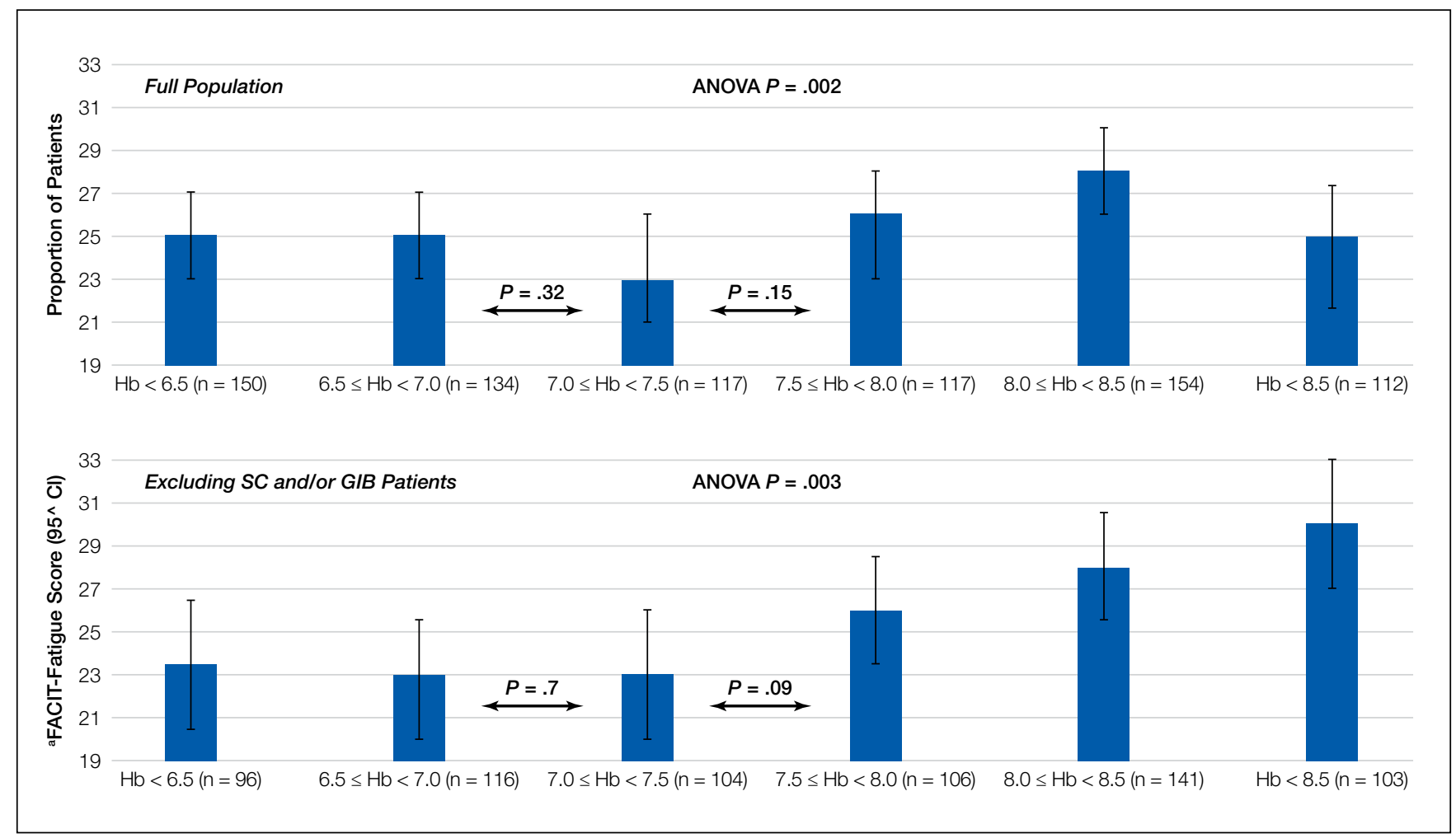

FIG. Mean fatigue score by minimum hemoglobin concentration.

NOTE: Abbreviations: ANOVA, analysis of variance; $\mathrm{Cl}$, confidence interval; GIB, gastrointestinal bleeding; $\mathrm{Hb}$, hemoglobin; $\mathrm{SC}$, sickle cell anemia.

aHigher FACIT fatigue subscale scores equate with lower fatigue

level. Patients with a minimum $\mathrm{Hb}<7 \mathrm{~g} / \mathrm{dL}$ were $50 \%$ (odds ratio $[\mathrm{OR}]=1.5 ; P=0.03$ ) more likely to have high fatigue and patients with a minimum $\mathrm{Hb} 7-8 \mathrm{~g} / \mathrm{dL}$ were $90 \%$ (OR $=1.9 ; \mathrm{P}<0.001)$ more likely to have high fatigue compared with patients with a minimum $\mathrm{Hb} \geq 8 \mathrm{~g} / \mathrm{dL}$ in Model 1 . These results were similar in Model 2, although the effect was only statistically significant in the 7-8 $\mathrm{g} / \mathrm{dL}$ Hb group (Table 3 ). When excluding SC and/or GIB patients, the odds of having high fatigue as minimum $\mathrm{Hb}$ decreased were the same or higher for both models compared to the full population of patients. However, again, in Model 2, the effect was only statistically significant in the 7-8 g/dL Hb group (Supplemental Table 1).

Patients with a mean $\mathrm{Hb}<8 \mathrm{~g} / \mathrm{dL}$ were $20 \%$ to $30 \%$ more likely to have high fatigue and patients with mean $\mathrm{Hb} 8-9$ $\mathrm{g} / \mathrm{dL}$ were $50 \%$ more likely to have high fatigue compared with patients with a mean $\mathrm{Hb} \geq 9 \mathrm{~g} / \mathrm{dL}$, but the effects were only statistically significant for patients with a mean $\mathrm{Hb} 8-9$ $\mathrm{g} / \mathrm{dL}$ in both Models 1 and 2 (Table 3). These results were similar when excluding patients with SC and/or GIB, but they were only significant for patients with a mean $\mathrm{Hb} 8-9 \mathrm{~g} /$ $\mathrm{dL}$ in Model 1 and patients with a mean $\mathrm{Hb}<8 \mathrm{~g} / \mathrm{dL}$ in the Model 2 (Supplemental Table 3).

\section{DISCUSSION}

These results demonstrate that minimum $\mathrm{Hb}$ during hospitalization is associated with fatigue in hospitalized patients age $\geq 50$ years, and the association is stronger among patients without SC and/or GIB as comorbidities. The analysis of $\mathrm{Hb}$ as a continuous and categorical variable and the use of both linear and logistic regression models support the robustness of these associations and illuminate their clinical significance. For example, in linear regression with minimum $\mathrm{Hb}$ a continuous variable, the coefficient of 1.4 suggests that an increase of $2 \mathrm{~g} / \mathrm{dL}$ in $\mathrm{Hb}$, as might be expected from transfusion of 2 units of red blood cells, would be associated with about a 3-point improvement in fatigue. Additionally, as a categorical variable, a minimum $\mathrm{Hb} \geq 8 \mathrm{~g} / \mathrm{dL}$ compared with a minimum $\mathrm{Hb}<7 \mathrm{~g} / \mathrm{dL}$ or $7-8 \mathrm{~g} / \mathrm{dL}$ is associated with a 3- to 4 -point improvement in fatigue. Previous literature suggests that a difference of 3 in the FACIT score is the minimum clinically important difference in fatigue, ${ }^{3}$ and changes in minimum $\mathrm{Hb}$ in either model predict changes in fatigue that are in the range of potential clinical significance.

The clinical significance of the findings is also reflected in the results of the logistic regressions, which may be mapped to potential effects on functional status. Specifically, the odds of having a high fatigue level (FACIT <27) increase $90 \%$ for persons with a minimum $\mathrm{Hb} 7-8 \mathrm{~g} / \mathrm{dL}$ compared with persons with a minimum $\mathrm{Hb} \geq 8 \mathrm{~g} / \mathrm{dL}$. For persons with a minimum $\mathrm{Hb}<7 \mathrm{~g} / \mathrm{dL}$, point estimates suggest a smaller (50\%) increase in the odds of high fatigue, but the $95 \%$ confidence interval overlaps heavily with the estimate of patients whose minimum $\mathrm{Hb}$ is $7-8 \mathrm{~g} / \mathrm{dL}$. While it might be 
TABLE 3. Minimum and Mean $\mathrm{Hb}$ Effect on Patient Fatigue $(\mathrm{N}=784)$

\begin{tabular}{|c|c|c|c|c|c|c|c|c|}
\hline Minimum $\mathrm{Hb}$ & Model & $\mathrm{Hb}$ Concentration & \multicolumn{3}{|c|}{ Inpatient Fatigue Level } & \multicolumn{3}{|c|}{ High Fatigue (FACIT<27) } \\
\hline & \multirow[t]{3}{*}{1} & Minimum $\mathrm{Hb}$ (continuous) & 1.4 & $(0.4,2.3)$ & .005 & 0.9 & $(0.8,1.0)$ & .09 \\
\hline & & $7 \mathrm{~g} / \mathrm{dL} \leq \mathrm{Hb}<8 \mathrm{~g} / \mathrm{dLa}$ & -4.1 & $(-6.6,-1.7)$ & $<.001$ & 1.9 & $(1.3,2.8)$ & $<.001$ \\
\hline & & $\mathrm{Hb}<7 \mathrm{~g} / \mathrm{dLa}$ & -4.2 & $(-6.6,-1.6)$ & $<.001$ & 1.5 & $(1.1,2.2)$ & .03 \\
\hline & \multirow{2}{*}{2} & $7 \mathrm{~g} / \mathrm{dL} \leq \mathrm{Hb}<8 \mathrm{~g} / \mathrm{dLa}$ & -3.9 & $(-6.3,-1.4)$ & .02 & 1.9 & $(1.3,2.7)$ & .001 \\
\hline & & $\mathrm{Hb}<7 \mathrm{~g} / \mathrm{dLa}$ & -3.2 & $(-5.7,-0.6)$ & .02 & 1.3 & $(0.9,1.9)$ & .21 \\
\hline \multirow[t]{6}{*}{ Mean $\mathrm{Hb}$} & & & \multicolumn{3}{|c|}{ Inpatient Fatigue Level } & \multicolumn{3}{|c|}{ High Fatigue (FACIT<27) } \\
\hline & Model & $\mathrm{Hb}$ Concentration & $\beta$ & $95 \% \mathrm{Cl}$ & $\mathrm{P}$ & OR & $95 \% \mathrm{Cl}$ & $P$ \\
\hline & 1 & $\mathrm{Hb}<8 \mathrm{~g} / \mathrm{dLb}$ & -2.4 & $(-5.1,0.4)$ & .09 & 1.2 & $(0.8,1.9)$ & .3 \\
\hline & \multirow[t]{3}{*}{2} & Mean $\mathrm{Hb}$ (continuous) & 0.4 & $(-0.9,1.6)$ & .6 & 1.0 & $(0.9,1.2)$ & .3 \\
\hline & & $8 \mathrm{~g} / \mathrm{dL} \leq \mathrm{Hb}<9 \mathrm{~g} / \mathrm{dLb}$ & -2.5 & $(-4.9,-0.2)$ & .04 & 1.5 & $(1.1,2.2)$ & .03 \\
\hline & & $H b<8 \mathrm{~g} / \mathrm{dLb}$ & -2.4 & $(-5.1,0.3)$ & .08 & 1.3 & $(0.8,1.9)$ & .27 \\
\hline \multicolumn{9}{|c|}{$\mathrm{Hb} \geq 8 \mathrm{~g} / \mathrm{dL}$. referent group. } \\
\hline \multicolumn{9}{|c|}{$\begin{array}{l}\text { NOTEE Linear/Logistic Regression Model 1: Adjusted for age, sex, time of minimum Hb relative to measurement of fatigue, comorbidities. Linear/Logistic Regression Model 2: Adjusted for age, sex, time of minimum Hb relative to measure } \\
\text { ment of fatigue, number of of complete blod countss drawn during hospitalization, comorbidities. Comorbidities: myocardial infarction, congestive heart failure, peripheral vascular disease, cerebrovascular disease, dementia, chronic } \\
\text { pulmonary disease, rheumatic disease, peptic ulcer disease, liver disease, diabetes, hemiplegia/paraplegia, renal disease, cancer, sickle cell anemia, gastrointestinal bleeding, depressive disorder. Abbreviations: Cl, confidence interval; } \\
\text { FACIT, Functional Assessment of Chronic lliness Therapy; } \mathrm{Hb} \text {, hemoglobin; OR, odds ratio. }\end{array}$} \\
\hline
\end{tabular}

expected that patients with a minimum $\mathrm{Hb}<7 \mathrm{~g} / \mathrm{dL}$ have greater levels of fatigue compared with patients with a minimum $\mathrm{Hb} 7-8 \mathrm{~g} / \mathrm{dL}$, we did not observe such a pattern. One reason may be that the confidence intervals of our estimated effects are wide enough that we cannot exclude such a pattern. Another possible explanation is that in both groups, the fatigue levels are sufficiently severe, such that the difference in their fatigue levels may not be clinically meaningful. For example, a FACIT score of 23 to 26 has been shown to be associated with an ECOG performance status of 2 to 3 , requiring bed rest for at least part of the day. ${ }^{3}$ Therefore, patients with a minimum $\mathrm{Hb} 7-8 \mathrm{~g} / \mathrm{dL}$ (mean FACIT score $=24$; Table 2 ) or a minimum $\mathrm{Hb}$ of $<7 \mathrm{~g} / \mathrm{dL}$ (mean FACIT score $=23$; Table 2 ) are already functionally limited to the point of being partially bed bound, such that further decreases in their $\mathrm{Hb}$ may not produce additional fatigue in part because they reduce their activity sufficiently to prevent an increase in fatigue. In such cases, the potential benefits of increased $\mathrm{Hb}$ may be better assessed by measuring fatigue in response to a specific and provoked activity level, a concept known as fatigability. ${ }^{20}$

That minimum $\mathrm{Hb}$ is more strongly associated with fatigue than any other measure of $\mathrm{Hb}$ during hospitalization may not be surprising. Mean, median, maximum, and discharge $\mathrm{Hb}$ may all be affected by transfusion during hospitalization that could affect fatigue. Admission $\mathrm{Hb}$ may not reflect true oxygen-carrying capacity because of hemoconcentration.

The association between $\mathrm{Hb}$ and fatigue in hospitalized patients is important because increased fatigue could contribute to slower clinical recovery in hospitalized patients. Additionally, increased fatigue during hospitalization and at hospital discharge could exacerbate the known deleterious consequences of fatigue on patients and their health outcomes $^{14,15}$ after hospital discharge. Although one previous study, the Functional Outcomes in Cardiovascular Patients Undergoing Surgical Hip Fracture Repair (FOCUS) ${ }^{8}$ trial, did not report differences in patients' fatigue levels at 30 and 60 days postdischarge when transfused at restrictive $(8 \mathrm{~g} / \mathrm{dL})$ compared with liberal $(10 \mathrm{~g} / \mathrm{dL}) \mathrm{Hb}$ thresholds, confidence in the validity of this finding is reduced by the fact that more than half of the patients were lost to follow-up at the 30-and 60 -day time points. Further, patients in the restrictive transfusion arm of FOCUS were transfused to maintain $\mathrm{Hb} \mathrm{lev}$ els at or above $8 \mathrm{~g} / \mathrm{dL}$. This transfusion threshold of $8 \mathrm{~g} / \mathrm{dL}$ may have mitigated the high levels of fatigue that are seen in our study when patients' $\mathrm{Hb}$ drops below $8 \mathrm{~g} / \mathrm{dL}$, and maintaining a $\mathrm{Hb}$ level of $7 \mathrm{~g} / \mathrm{dL}$ is now the standard of care in stable hospitalized patients. Lastly, FOCUS was limited to postoperative hip fracture patients, and the generalizability of FOCUS to hospitalized medicine patients with anemia is limited. 
Therefore, our results support guideline suggestions that practitioners incorporate the presence of patient symptoms such as fatigue into transfusion decisions, particularly if patients' $\mathrm{Hb}$ is $<8 \mathrm{~g} / \mathrm{dL} .{ }^{18}$ Though reasonable, the suggestion to incorporate symptoms such as fatigue into transfusion decisions has not been strongly supported by evidence so far, and it may often be neglected in practice. Definitive evidence to support such recommendations would benefit from study through an optimal trial ${ }^{18}$ that incorporates symptoms into decision making. Our findings add support for a study of transfusion strategies that incorporates patients' fatigue level in addition to $\mathrm{Hb}$ concentration.

This study has several limitations. Although our sample size is large and includes patients with a range of comorbidities that we believe are representative of hospitalized general medicine patients, as a single-center, observational study, our results may not be generalizable to other centers. Additionally, although these data support a reliable association between hospitalized patients' minimum $\mathrm{Hb}$ and fatigue level, the observational design of this study cannot prove that this relationship is causal. Also, patients' Hb values were measured at the discretion of their clinician, and therefore, the measures of $\mathrm{Hb}$ were not uniformly measured for participating patients. In

\section{References}

1. Yellen SB, Cella DF, Webster K, Blendowski C, Kaplan E. Measuring fatigue and other anemia-related symptoms with the Functional Assessment of Cancer Therapy (FACT) measurement system. J Pain Symptom Manage. 1997;13(2):63-74.

2. Cella D, Lai JS, Chang CH, Peterman A, Slavin M. Fatigue in cancer patients compared with fatigue in the general United States population. Cancer. 2002;94(2):528-538. doi:10.1002/cncr.10245.

3. Cella D, Eton DT, Lai J-S, Peterman AH, Merkel DE. Combining anchor and distribution-based methods to derive minimal clinically important differences on the Functional Assessment of Cancer Therapy (FACT) anemia and fatigue scales. J Pain Symptom Manage. 2002;24(6):547-561.

4. Tonelli M, Hemmelgarn B, Reiman $\mathrm{T}$, et al. Benefits and harms of erythropoiesis-stimulating agents for anemia related to cancer: a meta-analysis. CMAJ Can Med Assoc J J Assoc Medicale Can. 2009;180(11):E62-E71. doi:10.1503/ cmaj.090470.

5. Foley RN, Curtis BM, Parfrey PS. Erythropoietin Therapy, Hemoglobin Targets, and Quality of Life in Healthy Hemodialysis Patients: A Randomized Trial. Clin J Am Soc Nephrol. 2009;4(4):726-733. doi:10.2215/CJN.04950908.

6. Keown PA, Churchill DN, Poulin-Costello M, et al. Dialysis patients treated with Epoetin alfa show improved anemia symptoms: A new analysis of the $\mathrm{Ca}$ nadian Erythropoietin Study Group trial. Hemodial Int Int Symp Home Hemodial. 2010;14(2):168-173. doi:10.1111/j.1542-4758.2009.00422.x.

7. Palmer SC, Saglimbene V, Mavridis D, et al. Erythropoiesis-stimulating agents for anaemia in adults with chronic kidney disease: a network meta-analysis. Cochrane Database Syst Rev. 2014:CD010590.

8. Carson JL, Terrin ML, Noveck H, et al. Liberal or Restrictive Transfusion in high-risk patients after hip surgery. N Engl J Med. 2011;365(26):2453-2462. doi:10.1056/NEJMoa1012452.

9. Holst LB, Haase N, Wetterslev J, et al. Transfusion requirements in septic shock (TRISS) trial - comparing the effects and safety of liberal versus restrictive red blood cell transfusion in septic shock patients in the ICU: protocol for a randomised controlled trial. Trials. 2013;14:150. doi:10.1186/1745-6215-14-150.

10. Hébert PC, Wells G, Blajchman MA, et al. A multicenter, randomized, controlled clinical trial of transfusion requirements in critical care. $N$ Engl J Med. 1999;340(6):409-417. doi:10.1056/NEJM199902113400601.

11. Corwin HL, Theus JW, Cargile CS, Lang NP. Red blood cell transfusion: Impact of an education program and a clinical guideline on transfusion practice. J Hosp Med. 2014;9(12):745-749. doi:10.1002/jhm.2237.

12. Saxena, S, editor. The Transfusion Committee: Putting Patient Safety First, 2nd Edition. Bethesda (MD): American Association of Blood Banks; 2013.

13. The 2011 National Blood Collection and Utilization Report. http://www.hhs.gov/ addition, fatigue was only measured at one time point during a patient's hospitalization, and it is possible that patients' fatigue levels change during hospitalization in relation to variables we did not consider. Finally, our study was not designed to assess the association of $\mathrm{Hb}$ with longer-term functional outcomes, which may be of greater concern than fatigue.

\section{CONCLUSION}

In hospitalized patients $\geq 50$ years old, minimum $\mathrm{Hb}$ is reliably associated with patients' fatigue level. Patients whose minimum $\mathrm{Hb}$ is $<8 \mathrm{~g} / \mathrm{dL}$ experience higher fatigue levels compared to patients whose minimum $\mathrm{Hb}$ is $\geq 8 \mathrm{~g} / \mathrm{dL}$. Additional studies are warranted to understand if patients may benefit from improved fatigue levels by correcting their anemia through transfusion.

Disclosure: Dr. Prochaska is supported by an Agency for Healthcare Research and Quality Patient-Centered Outcomes Research Institutional K12 Award (1K12HS023007-01, principal investigator Meltzer). Dr. Meltzer is supported by a National Institutes of Health Clinical and Translational Science Award (2UL1TR000430-06, principal investigator Solway) and a grant from the Patient-Centered Outcomes Research Network in support of the Chicago Patient-Centered Outcomes Research Network. The authors report no conflicts of interest.

ash/bloodsafety/2011-nbcus.pdf. Accessed August 16, 2017.

14. Vestergaard S, Nayfield SG, Patel KV, et al. Fatigue in a Representative Population of Older Persons and Its Association With Functional Impairment, Functional Limitation, and Disability. J Gerontol A Biol Sci Med Sci. 2009;64A(1):76-82. doi:10.1093/gerona/gln017.

15. Gill TM, Desai MM, Gahbauer EA, Holford TR, Williams CS. Restricted activity among community-living older persons: incidence, precipitants, and health care utilization. Ann Intern Med. 2001;135(5):313-321.

16. Koch CG, Li L, Sun Z, et al. Hospital-acquired anemia: Prevalence, outcomes, and healthcare implications. J Hosp Med. 2013;8(9):506-512. doi:10.1002/jhm.2061.

17. Meltzer D, Manning WG, Morrison J, et al. Effects of Physician Experience on Costs and Outcomes on an Academic General Medicine Service: Results of a Trial of Hospitalists. Ann Intern Med. 2002;137(11):866-874. doi:10.7326/0003-4819. 137-11-200212030-00007.

18. Carson JL, Grossman BJ, Kleinman S, et al. Red Blood Cell Transfusion: A Clinical Practice Guideline From the AABB*. Ann Intern Med. 2012;157(1):49-58. doi:10.7326/0003-4819-157-1-201206190-00429.

19. Moreh E, Jacobs JM, Stessman J. Fatigue, function, and mortality in older adults. J Gerontol A Biol Sci Med Sci. 2010;65(8):887-895. doi:10.1093/gerona/glq064.

20. Eldadah BA. Fatigue and Fatigability in Older Adults. PMER. 2010;2(5):406413. doi:10.1016/j.pmrj.2010.03.022

21. Hardy SE, Studenski SA. Fatigue Predicts Mortality among Older Adults. J Am Geriatr Soc. 2008;56(10):1910-1914. doi:10.1111/j.1532-5415.2008.01957.x.

22. Pfeiffer E. A short portable mental status questionnaire for the assessment of organic brain deficit in elderly patients. J Am Geriatr Soc. 1975;23(10):433-441.

23. Quan $\mathrm{H}$, Sundararajan V, Halfon $\mathrm{P}$, et al. Coding algorithms for defining comorbidities in ICD-9-CM and ICD-10 administrative data. Med Care. 2005;43(11):1130-1139.

24. HCUP Clinical Classifications Software (CCS) for ICD-9-CM. Healthcare Cost and Utilization Project (HCUP). 2006-2009. Agency for Healthcare Research and Quality, Rockville, MD. https://www.hcup-us.ahrq.gov/toolssoftware/ccs/ccs. jsp. Accessed November 22, 2016

25. Cella DF, Tulsky DS, Gray G, et al. The Functional Assessment of Cancer Therapy scale: development and validation of the general measure. J Clin Oncol Off J Am Soc Clin Oncol. 1993;11(3):570-579.

26. Webster K, Cella D, Yost K. The Functional Assessment of Chronic Illness Therapy (FACIT) Measurement System: properties, applications, and interpretation. Health Qual Life Outcomes. 2003;1:79. doi:10.1186/1477-7525-1-79.

27. Oken MMMD a, Creech RHMD b, Tormey DCMD, et al. Toxicity and response criteria of the Eastern Cooperative Oncology Group. J Clin Oncol. 1982;5(6): $649-656$. 